CREATIVE CONTROL 



\title{
Creative Control
}

THE AMBIVALENCE OF WORK IN THE CULTURE INDUSTRIES

Michael L. Siciliano

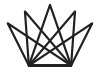 \\ Columbia University Press \\ New York
}




$$
\begin{gathered}
\text { Columbia University Press } \\
\text { Publishers Since } 1893 \\
\text { New York Chichester, West Sussex } \\
\text { cup.columbia.edu } \\
\text { Copyright @ } 2021 \text { Columbia University Press } \\
\text { All rights reserved } \\
\text { Library of Congress Cataloging-in-Publication Data } \\
\text { Names: Siciliano, Michael L., author. }
\end{gathered}
$$

Title: Creative control : the ambivalence of work in the culture industries / Michael L. Siciliano.

Description: New York : Columbia University Press, [2021] | Includes bibliographical references and index.

Identifiers: LCCN 2020045830 (print) | LCCN 2020045831 (ebook) |

ISBN 9780231193801 (hardback; alk. paper) | ISBN 9780231193818 (trade paperback; alk. paper) |

ISBN 9780231550512 (ebook)

Subjects: LCSH: Cultural industries. | Creative ability. | Creative ability in business. |

Work-Psychological aspects.

Classification: LCC HD9999.C9472 S525 2021 (print) | LCC HD9999.C9472 (ebook) |

DDC 658.3/14-dc23

LC record available at https://lccn.loc.gov/2020045830

LC ebook record available at https://lccn.loc.gov/2020045831

Columbia University Press books are printed on permanent and durable acid-free paper.

Printed in the United States of America

Cover design: Noah Arlow

Cover image: Shutterstock (seesaw) 